\title{
MOTIVASI INTRINSIK DAN EKSTRINSIK DALAM PEMBELAJARAN BAHASA ARAB
}

\author{
Oleh: \\ Amirul Mukminin \\ Fakultas Tarbiyah IAI Ibrahimy Situbondo \\ Amirelghafur@yahoo.co.id
}

\begin{abstract}
In the process of teaching and learning will definitely be an interaction between teachers and students, which teachers act as informants, mentor, motivator, facilitator, mediator, and evaluators. Motivator is the most important role of teachers in fostering the spirit of students to learn. In addition to the interaction with the teacher and the student, the learning process also there is interaction with the environment, and the environment also affects the emergence of a sense of fun in the learning process. MTs Salafiyah Syafi'iyah Sukorejo Situbondo and MTs SA Al-Hidayah Kota Batu - Malang are the two institutions that have a strong interaction among teachers, students, and the environment that cause students delighted in learning, especially in learning Arabic. Therefore, the researchers made these two institutions as a model of learning Arabic in junior level. In the present study, researcher intend to describe, examine and analyze student motivation in learning Arabic in junior Salafiyah Shafi'ites Sukorejo Situbondo and MTs SA Al-Hidayah Batu-Malang.
\end{abstract}

Key words: Motivation, Learning, Arabic

\section{A. Pendahuluan}

Pendidikan dari jaman ke jaman mempunyai peranan yang amat penting. Dalam undang-undang nomor 20 tahun 2003 tentang sistem pendidikan nasional pada pasal 1 ayat (1) menyebutkan bahwa pendidikan adalah usaha sadar untuk mewujudkan suasana belajar dan proses pembelajaran agar peserta didik secara aktif mengembangkan potensi dirinya untuk memiliki kekuatan spiritual keagamaan, pengendalian diri, kepribadian, kecerdasan, akhlak mulia, serta ketrampilan yang diperlukan dirinya, masyarakat, bangsa dan negara. ${ }^{1}$

1 UURI No. 20 Tahun, Tentang Sistem Pendidikan Nasional, (Jakarta, Kreasi Jaya Utama, 2003), Bisa juga lihat di: Fuad Ihsan, Dasar-dasar Kependidikan, (Jakarta, Rineka 
Berdasarkan undang-undang diatas bahwa pendidkan tidak terlepas dari adanya belajar dan mengajar, namun masalah belajarmengajar sejak dulu sampia sekarang terus-menerus benyak mendapatkan perhatian, baik di kalangan pakar ilmu pendidikan dan psikologi yang melihatnya dari sudut pedagogis ${ }^{2}$ dan psikologis $^{3}$ maupun di kalangan praktisi pendidikan, seperti guru, penilik, konselor, dan para pengelola pendidikan. Dasar pertimbangan utama dan bersifat umum adalah belajar dan mengajar ${ }^{4}$ berlangsung secara interaktif yang melibatkan berbagai komponen yang saling konsisten satu dengan yang lainnya untuk mencapai tujuan pengajaran yang telah ditetapkan.

Berbagai pendekatan telah digunakan dalam rangka studi yang mendalam dan meluas terhadap masalah tersebut, antara lain dari sudut hukum sebab-akibat, hukum normatif, dan hukum probabilitas. Berdasarkan hukum sebab akibat diajukan konsep bahwa karena guru mengajar, maka siswa belajar. Berdasarkan hukum normatif diajukan konsep bahwa belajar dan mengajar harus dilandaskan norma-norma etis, melalui proses yang baik diharapkan tercipta hasil yang baik pula, yakni baik dalam ukuran normatif yang berlaku pada masa itu. Berdasarkan hukum probabilitas diajukan konsep bahwa belajar dan mengajar dilakukan oleh manusia (anak didik dan pendidik) yang memiliki berbagai kemungkinan karena adanya minat, aspirasi, kebutuhan, dan situasi yang senantiasa berubah. Perilaku belajar mengajar juga mengandung berbagai kemungkian. ${ }^{5}$ Pendekatan terakhir ini lebih menitik beratkan tinjauan

Cipta, 2003), hlm. 229.

2 Istilah Pedagogis dalam pendidikan berarti Pedagogi yang artinya adalah pendidikan, Pedagogi beraal dari bahasa Yunani "Pedagogia" yang berarti pergaulan dengan anak-anak. Fuad Ihsan, Dasar-dasar Kependidikan, hlm. 1.

3 Istilah Psikologis yang berarti psikologi berasal dari bahasa Yunani psyce yang artinya jiwa, sedangkan logy atau logos yang artinya adalah ilmu atau pengetahuan. Abu Ahmadi dan Widodo Supriono, Psikologi Belajar, (Jakarta, Rineka Cipta, 2003), hlm. 01; Menukil istilah Sukmadita, " bahwa psikologi adalah sebagai suatu studi atau ilmu yang mempelajari kegiatan atau perilaku dalam interaksi dengan lingkungan." Nana Syaodih Sukmadinata, Landasan Psikologi Proses Pendidikan, (Bandung, Remaja Rosdakarya, 2003), hlm. 18 .

4 Kata Belajar identik dengan siswa atau anak didik, sehingga belajar dapat diartikan suatu proses perbuatan, bereaksi, memahami berkat adanya pengalaman, sedangkan pengalaman pada dasarnya ialah interaksi antara individu dengan lingkungan. Sedangkan kata mengajar adalah membimbing kegiatan belajar anak, mengajar identic dengan Guru. Oemar Hamalik, Psikologi Belajar dan Mengajar, (Bandung, Sinar Baru Agensindo, 2009), hlm. 58.

${ }^{5}$ Oemar Hamalik, Psikologi Belajar dan Mengajar, (Bandung, Sinar Baru Algensindo, 2009), hlm. 5. 
belajar dan mengajar dari konteks psikologis.

Untuk menyiapkan peserta didik yang bermutu maka diperlukan motivasi belajar pada setiap siswa. Baik terhadap siswa yang pandai dan terlebih pada siswa yang tingkat intelegensinya rendah perlu mendapatkan dukungan agar termotivasi dalam mengikuti kegiatan belajar mengajar di sekolah.

Motivasi merupakan hal yang penting dalam proses pembelajaran karena keberadaanya sangat berarti bagi perbuatan belajar. Selain itu motivasi belajar merupakan faktor psikis yang dapat menumbuhkan gairah, menimbulkan perasaan senang dan semangat untuk belajar. Hasil belajar akan menjadi optimal kalau ada motivasi. Makin tepat motivasi yang diberikan, maka akan berhasil pula proses belajar siswa. Jadi motivasi akan senantiasa menentukan intensitas usaha belajar bagi para siswa. Menukil istilah Sardiman, bahwa motivasi akan menyebabkan terjadinya suatu perubahan energi yang ada pada diri manusia, sehingga akan bergayut dengan persoalan gejala kejiwaan, perasaan dan juga emosi, untuk kemudian bertindak atau melakukan sesuatu. Di dalam kegiatan belajar mengajar peranan motivasi baik intrinsik maupun ekstrinsik sangat diperlukan. ${ }^{6}$ Motivasi selain dapat mengembangkan aktivitas siswa juga dapat mengarahkan dan memelihara ketekunan dalam melakukan kegiatan belajar. Siswa yang memiliki motivasi yang kuat dalam belajar akan menunjukkan hasil belajar yang baik. Adanya usaha yang tekun dan terutama didasari dengan adanya motivasi, maka individu yang belajar itu akan melahirkan prestasi yang baik. Intensitas motivasi seorang siswa akan sangat menentukan tingkat pencapaian prsetasi belajarnya. Namun apabila siswa tidak memiliki motivasi yang kuat maka hasil belajar yang dicapai juga tidak akan optimal, dalam hal ini siswa akan mengalami kegagalan belajar.

Siswa yang kurang memiliki motivasi dalam belajar dapat dilihat melalui ciri-ciri diantaranya sebagai berikut: jarang mengerjakan tugas, mudah putus asa, harus memerlukan dorongan dari luar untuk berprestasi (kurang ada dorongan dari dalam diri sendiri), cepat puas dengan prestasinya, kurang semangat belajar, tidak mempunyai semangat untuk mengejar cita-cita, tidak senang mencari dan memecahkan soal-soal atau masalah.

Bagi siswa yang mempunyai motivasi intrinsik, ${ }^{7}$ mereka akan

\footnotetext{
${ }^{6}$ Sardiman, Interaksi dan Motivasi Belajar, (Jakarta, Raja Grapindo Persada, 2003), hlm. 74

7 Yang dimaksud dengan motivasi intrinsik adalah motif-motif yang menjadi aktif atau
} 
memiliki kesadaran sendiri untuk memperhatikan penjelasan dari guru. Rasa ingin tahunya lebih banyak terhadap materi pelajaran yang diberikan. Siswa yang demikian tidak akan mudah mendapatkan pengaruh gangguan dari sekitarnya. Lain halnya bagi siswa yang tidak ada motivasi di dalam dirinya, maka motivasi ekstrinsik ${ }^{8}$ yang merupakan dorongan dari luar dirinya mutlak diperlukan. Di sini tugas guru pembimbing adalah membangkitkan motivasi peserta didik sehingga mereka mau belajar.

Kebanyakan dari peserta didik mulai dari tingkat SD/MI sampai pada tingkat Perguruan Tinggi menganggap materi bahasa Arab sebagai mata pelajaran yang menakutkan, pelajaran yang begitu linier, menjemukan, dan memberatkan karena terlalu banyak dibebani dengan sederet hafalan teks, ${ }^{9}$ sehingga kebanyakan dari mereka enggan untuk belajar bahasa Arab. Namun berbeda dengan para siswa MTs Salafiyah Syafi'iyah Sukorejo Situbondo, sebagaimana hasil mulahadzah peneliti pada bulan Juni tahun 2011, bahwa mereka memiliki kesenangan dan semangat dalam mempelajari bahasa Arab, hal ini bisa terlihat ketika dalam proses pembelajaran berlangsung, para siswa sangat aktif mengikuti pelajaran dan juga senang mengerjakan tugas.

Selain MTs Salafiyah Syafi'iyah Sukorejo Situbondo, terdapat juga MTs SA Al-Hidayah Kota Batu-Malang yang siswanya mempunya semangat tinggi dalam mempelajari bahasa Arab. Dua lembaga ini dianggap unik dan layak untuk diteliti agar menjadi model bagi lembaga yang lain dalam pembelajaran bahasa Arab.

Penelitian ini bermaksud untuk menggambarkan, mengkaji dan menganalisis motivasi siswa dalam pembelajaran bahasa Arab. Oleh sebab itu, permasalahan yang diangkat dalam penelitian ini adalah bagaimana motivasi siswa MTs Salafiyah Syafi'iyah Sukorejo Situbondo dan MTs SA Al-Hidayah Kota Batu-Malang?

Pendekatan penelitian yang digunakan merupakan pendekata penelitian kualitatif, peneliti berkeinginan mendeskripsikan, memahami makna-makna dibalik fenomena yang terjadi secara alamiah di lapangan

berfungsinya tidak perlu dirangsang dari luar, karena dalam setiap individu sudah ada dorongan untuk melakukan sesuatu. Syaiful Bahri Djamarah, Prestasi Belajar dan Kompetensi Guru, (Surabaya, Usaha Nasional, 1994), hlm. 35.

8 Motivasi ekstrinsik adalah dorongan terhadap perilaku seseorang yang ada di luar yang dilakukannya. Orang berbuat sesuatu karena dorongan dari luar seperti adanya hadiah hukuman dan sebagainya. Dimyati dan Mudjiono, Belajar dan Pembelajaran, (Jakarta, Rineka Cipta, 2002), hlm. 91.

9 Radliyah Zaenuddun, dkk. Metodologi dan Strategi Alternatif Pembelajaran Bahasa Arab, (Yogyakarta, Pustaka Rihlah Group, 2005), hlm. 19. 
dan menganalisisnya. Jenis penelitian ini adalah studi kasus, dengan sumber data primer berupa fenomena alamiyah dan informasi lisan, dengan teknik pengumpulan data menggunakan observasi partisipatif dan deep interview.

\section{B. Pembahasan}

\section{Motivasi Intrinsik dalam Pembelajaran Bahasa Arab}

Di MTs Salafiyah Syafi'iyah Sukorejo Situbondo, berdasarkan data yang diperoleh bahwa para siswa senang terhadap bahasa Arab dan mereka memiliki motivasi yang tinggi dalam mempelajarinya. Mereka berargumen bahwa: bahasa Arab merupakan bahasa al-Qur'an, bahasa ahli surga, dan karena mereka ingin melanjutkan pendidikan ke Timur tengah, Saudi Arabiyah misalnya.

Di MTs SA Al-Hidayah Kota Batu-Malang, berdasarkan data yang diperoleh bahwa para siswa senang juga terhadap bahasa Arab dan memiliki motivasi yang tinggi dalam mempelajarinya bahasa Arab tersebut. Mereka berargumen bahwa: bahasa Arab merupakan bahasa alQur'an, ingin melancong ke Negara Arab secara gratis, ingin menjadi ulama dan dai yang popular, dan mereka juga ingin melanjutkan pendidikan ke Timur tengah.

Berdasarkan penjelasan diatas, motivasi intrinsik dalam pembelajaran bahasa Arab di dua lembaga tersebut terdapat dua kesamaan argumen, pertama, karena bahasa Arab merupakan bahasa alQur'an. Kedua, karena para siswa ingin melanjutkan pendidikan ke Timur Tengah.

Namun selain dua persamaan tersebut, terdapat perbedaan lain, yaitu karena bahasa Arab merupakan bahasa ahli surga. Alasan tersebut terdapat di MTs Salafiyah Syafi'iyah Sukorejo Situbondo. Bedahalnya dengan para siswa MTs SA Al-Hidayah Kota Batu-Malang, mereka beralasan ingin melancong ke Negara Arab secara gratis dan ingin menjadi ulama dan dai yang popular.

Argumen bahwa bahasa Arab merupakan bahasa al-Qur'an memang pantas jika dijadikan sebagai pijakan awal untuk belajar bahasa Arab. Sebab al-Qur'an memang berbahasa Arab, meski di dalamnya terdapat bahasa Ibrani, Persi, dan sebagainya, namun itu hanya dapat dihitung dengan jari. Al-Qur'an merupakan paling shahihnya bahasa, Allah SWT. Berfirman: 


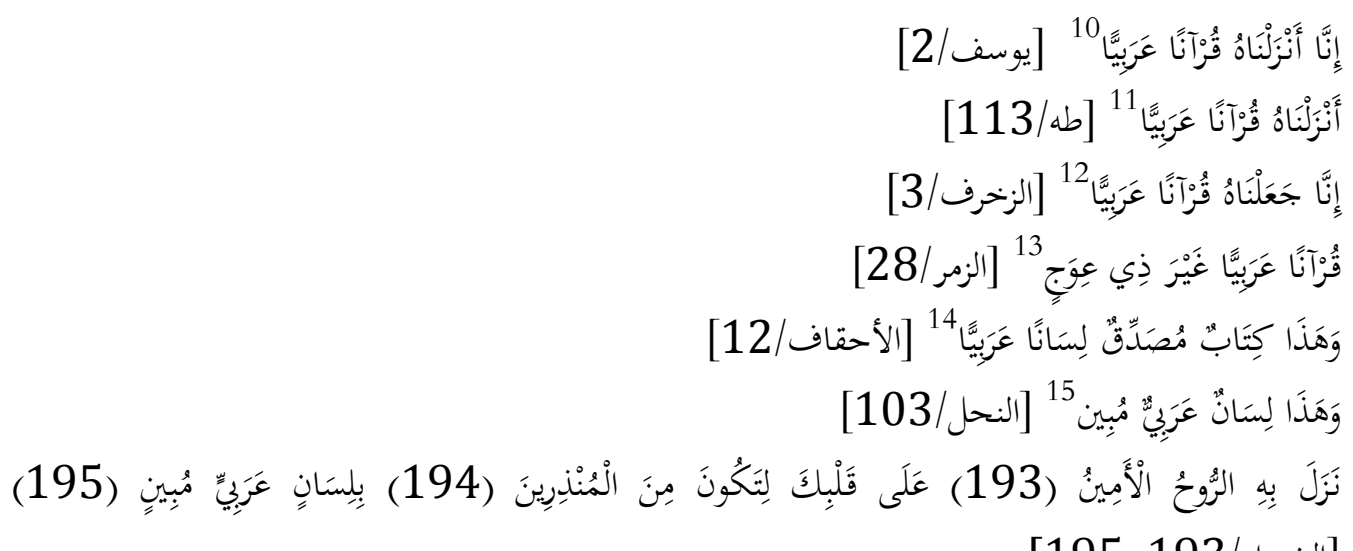

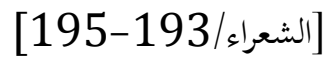

Untuk memahami al-Qur'an dan menggali makna yang tersimpan didalamnya, maka suatu keharusan untuk mempelajari bahasa Arab. Sebagaimana dalam suatu kaidah yang berbunyi:

ما لا يتم الواجب إلا به فهو واجب. 16

Karena al-Qur'an merupakan sumber utama dalam syariat Islam, maka mempelajari dan memahaminya merupakan suatu kewajiban bagi umat Islam, tidak akan dapat memahami al-Qur'an kalau tidak memahami bahasa Arab, karena al-Qur'an merupakan bahasa Arab, oleh sebab itulah mempelajari bahasa Arab merupakan suatu kewajiban, sebagaimana juga yang telah terungkap dalam kaidah diatas. Dalam ilmu mantiq dapat

\footnotetext{
${ }^{10}$ QS. Yusuf (12): 2

${ }^{11}$ QS. Thaahaa (20): 113

${ }^{12}$ QS. Az-Zukhruf (43): 3

${ }^{13}$ QS. Az-Zumar (39): 28

${ }^{14}$ QS. Al-Ahqaf (46): 12

${ }^{15}$ QS. An-Nahl (16): 103
}

${ }^{16}$ Tanpa memandang perselisihan dari kaidah tersebut, bahwa ada yang mengatakan يتم الواجب إلا به غير واجب pendapat ini dipelopori oleh golongan mu’tazilah dan sebgian pengikut madzhab Syafi'iyah seperti al-Juwaini. Setidaknya terdapat tiga kategori dalam hal kewajiban tersebut, yaitu apakah hal yang menjadi penyempurna dari suatu kewajiban tersebut merupakan bagian dari kewajiban tersebut? Ataukah syarat dari kewajiban tersebut? Ataukah suatu kepastian dari kewajiban tersebut?. Untuk memahami lebih dalam tentang peselisihan tersebut silahkan baca literatur-literatur ushul fiqh atau qawaidul fiqh. Semisal: Badru ad-Din Muhammad bin 'Abdullah al-Zarkasyi, al-Bahru al-Muhith fi Ushul al-Fiqh, Juz I, Cet., Ke-1, (Bairut, Dar al-Kutub al-'Ilmiyah, 2000), hlm. 254; Ibn Liham al-Ba'ily al-Damasyqy alHambaly, al-Qawaid wa al-Fawaid al-Ushuliyah wa Ma Yatbi'uha min al-Ahkam alFar'iyyah, Juz I, (Maktabah al-Madinah, 1999), hlm. 250; Muhammad bin Buhadir bin 'Abdillah az-Zarkasyi Abu Abdillah, , al-Manstur fi al-Qawaid, Juz I, Cet., Ke-3, (Kuwait, Wazara al-Auqaf wa as-Syuun al-Islamy, 1405 H), hlm. 235.

$130 \mid$ JURNAL LISAN AL-HAL 
digambarkan sebagai berikut:

al-Qur'an adalah bahasa Arab

Memahami al-Qur'an adalah wajib

Maka memahami bahasa Arab adalah wajib juga

Argumen bahwa para siswa ingin melanjutkan pendidikan ke Timur Tengah membuat mereka semangat dan secara inten belajar bahasa Arab demi mengejar cita-citanya, sebab mereka ataupun guru mereka akan merasa senang jika cita-citanya tercapai. Motivasi intrinsik ini sangatlah kuat dan akan membuat siswa aktif dalam mengikuti proses pembelajaran bahasa Arab.

Mereka tidak akan bisa menlanjutkan pendidikan ke Timur Tengah jika mereka tidak dapat berbicara bahasa Arab, sebab berbicara bahasa Arab merupakan syarat muthlaq yang harus dipenuhi bagi setiap anak didik yang ingin menlajutkan pendidikan ke daerah Timur Tengah.

Termasuk dalam motivasi intrinsik dalam pembelajaran bahasa Arab di MTs SA Al-Hidayah Kota Batu-Malang, adalah bahwa para siswa ingin melancong ke Negara Arab secara gratis. Keinginan tersebut telah mendorong siswa untuk belajar bahasa Arab dengan rajin dan tekun, terlebih ketika mereka membaca materi pembelajaran yang bercerita tentang melancong dan tanpa biaya sedikitpun, tidak heran jika ini merupakan salah satu dari motivasi intrinsik.

Termasuk dalam motivasi intrinsik dalam pembelajaran bahasa Arab di MTs SA Al-Hidayah Kota Batu-Malang, adalah bahwa para siswa ingin menjadi ulama dan dai yang popular. Keinginan tersebut merupakan suatu tujuan dalam hidup yang harus direalisasikan dan mereka baru akan merasa puas ababila tujuannya tercapai, sebagaimana yang telah dikatakan oleh Oemar hamalik dalam bukunya, Proses Belajar Mengajar, bahwa suatu tujuan dapat membangkitkan motivasi. ${ }^{17}$ Sehingga tujuan untuk menjadi ulama atau dai akan menimbulkan motivasi dalam diri seseorang untuk belajar ilmu agama secara mendalam, sehingga mereka akan dapat menyelesaikan berbagai problematika umat, dan Allah akan senantiasa meningkatkan derajad orang-orang yang berilmu, sebagaimana dalam firman-Nya:

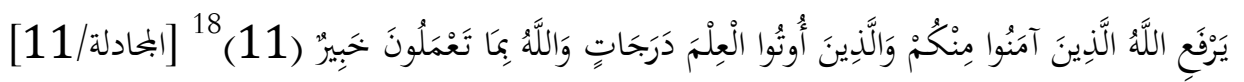

Dalam ayat yang lain Allah menjelaskan tentang perbedaan orang

\footnotetext{
${ }^{17}$ Oemar Hamalik, Proses Belajar Mengajar, Cet, Ke-15, (Jakarta, Bumi Aksara, 2013), hlm. 160 .

${ }^{18}$ QS. Al-Mujadalah (58): 11
} 
yang berilmu dengan orang yang tidak berilmu, terkadang dengan menggunakan pengandaian dan terkadang juga dengan secara langsung:

$$
\begin{aligned}
& \text { هَلْ يَسْتَوِي الْالَعْمَى وَالْبَصِيرُ } 19 \text { [الأنعام/50] }
\end{aligned}
$$

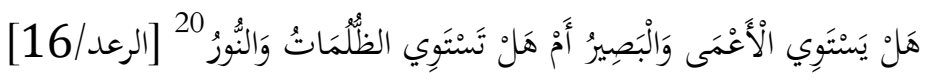

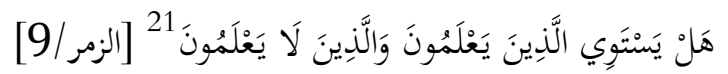

Ayat tersebut mengandung pertanyaan, apakah sama orang yang buta dengan orang yang melihat? Tentu jawabnya tidaklah sama. Begitu juga, apakah sama kegelapan dengan cahaya? Tentu juga tidak sama. Pada ayat yang terakhir, apakah sama orang yang tau dengan orang yang tidak tau? Jawabannya pun juga sudah barang tentu tidak sama. Disinilah, sesuai dengan yang menjadi tujuan dari belajar bahasa Arab yang menjadi motivasi para siswa di MTs SA Al-Hidayah Kota Batu-Malang akan mendorong mereka untuk menjadi orang-orang yang tau atau orang-orang yang berilmu, sehingga mereka akan ditinggikan derajadnya sesuai dengan firman-Nya dalam surat al-Mujadalah diatas. Rasulullah saw. Pun juga bersabda:

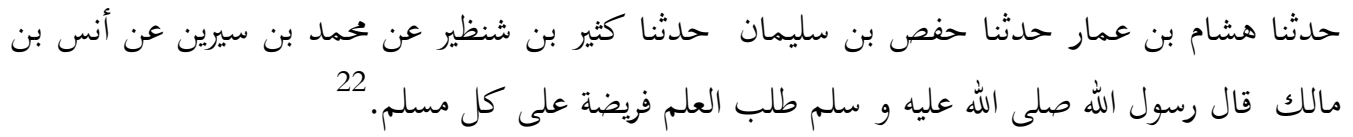

Hadis diatas menjelaskan bahwa seorang muslim wajib menuntut ilmu. Sebagian ulama salaf menjelaskan bahwa kewajiban menuntut ilmu sejak baru lahir sampai meninggal:

$$
\text { يقول بعض السلف : اطلب العلم من المهد إلى اللحد، أي منذ الطفولة إلى الموت.23 }
$$

${ }^{19}$ QS. Al-An'am (6): 50

${ }^{20}$ QS. Ar-Ra'd (13): 16

${ }^{21}$ QS. Az-Zumr (39): 9

22 Ungkapan اطلب العلم من المهد إلى اللحد memang ada sebagian yang mengkultus sebagai hadis, namun itu tidaklah benar, sebab pengkultusan tersebut tidak ada sanad yang sampai pada rasulullah. Secara tegas Syaikh 'Abdul Fattah Abu Ghuddah, 'ulama hadits kontemporer, lahir tahun $1336 \mathrm{H}$ dan wafat tahun 1417 H., dalam kitabnya, Qimah az-Zaman 'inda al-'Ulama, dan beberapa ulama lain menyatakan bahwa "Perkataan ini, yaitu 'menuntut ilmu dari buaian sampai ke liang lahad', dan disampaikan juga dengan ungkapan 'tuntutlah ilmu dari buaian sampai liang lahad', bukanlah hadits Nabi. Ia hanyalah perkataan manusia biasa, dan tidak boleh menyandarkannya kepada Rasulullah saw. sebagaimana yang dilakukan oleh sebagian orang. Sebab tidak ada yang boleh dinisbahkan kepada Rasulullah saw. kecuali perkataan, perbuatan dan persetujuan beliau." Lih: 'Abdul Fattah Abu Ghuddah, Qimah az-Zaman 'inda al- 'Ulama, Cet, ke-10, Maktab al-Mathbu'at al-Islamiyah, hlm. 30; Muhammad bin Yazid Abu 'Abdillah al-Quzwaini, Sunan Ibn Majah, Juz I, Bairut, Dar al-Fikr, hlm. 81.

132 JURNAL LISAN AL-HAL 
Dalam dunia pendidikan psikologi dijelaskan bahwa pendidikan anak bukan hanya sejak lahir, namun pendidikan yang paling bagus dan paling cepat dan melekat adalah sejak berada di kandungan sampai lahir sekitar usia 2 tahun. Dalam hadis lain dijelaskan:

$$
\text { قال من يرد الله به خيرا يفقه في الدين. إسناده صحيح على شرط الشيخين. } 24
$$

Bahwa seseorang yang dikendaki menjadi orang baik oleh Allah, niscaya dia akan diberi pemahaman, pengetahuan tentang agama Islam, dana dalamproses memcapai pemahaman dan pengetahuan tersebut akan dimudahkan jalannya dan kelak akan masuk surga. Tak heran jika yang majadi salah satu motivasi intrinsik dalam pembelajaran bahasa Arab bagi para siswa di MTs Salafiyah Syafi'iyah Sukorejo Situbondo, adalah bahwa bahasa Arab merupakan bahasa ahli surga, sebab bahasa Arab merupakan kunci untuk memahami berbagai sumber ilmu Islam, baik yang terdapat dalam al-Qur'ah, al-hadist, maupun peninggalan-peninggalan ulama salaf yang tertuang dalam karya-karyanya yang popular disebut dengan kitab kuning.

Rasulullah saw. Bersabda tentang orang yang menempuh jalan untuk memcapai pemahaman dan pengetahuan dalam Islam:

$$
\begin{aligned}
& \text { من سلك طريقا يلتمس فيه علما سهل الله له به طريقا إلى الجنة. وإن الملائكة لتضع أجنحتها رضا لطالب }
\end{aligned}
$$

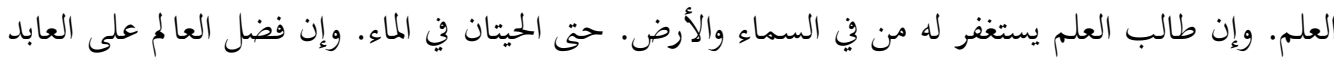

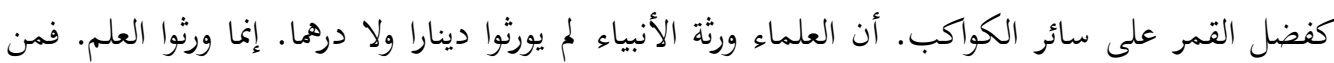

$$
\begin{aligned}
& \text { أخذه أخذ بكظ وافر. }
\end{aligned}
$$

Berdasarkan hadis diatas, jelaslah bahwa orang yang menempuh jalan untuk mencapai pemahaman dan pengetahuan tentang agama Islam maka akan dimasukkan ke surga, para malaikat akan melindungi mereka dan seluruh penghuni langit dan bumi akan memintakan ampun kepada mereka tanpa terkecuali sampai ikan-ikan dilaut pun dan ulat yang hidup di batu pun juga akan selalu dan senantiasa mendoakan orang yang mencari ilmu. Kalau ulama merupakan penerus para Nabi, maka hlm. 237.

${ }^{23}$ Aly bin Nayif asy-Syuhud, al-Waqtu wa Ahammiyatuhu fi Hayati al-Muslim, Juz III,

${ }^{24}$ Ahmad bin Hambal Abu 'Abdillah asy-Syaibany, Musnad al-Imam Ahmad bin Hambal, Juz II, Kairo, Muassasah Qurthubah, hlm. 234.

${ }^{25}$ Abi Daud Sulaiman bin Asy'ats as-Sajsatany, Sunan Abi Daud, Juz III, Bairut, Dar alFikr, hlm. 356; al-Quzwaini, Sunan Ibn Majah, hlm. 81; Abi 'Isa Muhammad bin 'Isa bin Surah al-Tirmidzy, Sunan al-Tirmidzy, Juz IV, Bairut, Dar al-Fikr, hlm. 153. 
merupakan suatu kewajiban untuk menuntut ilmu, sebab Nabi tidak mewariskan harta benda, melainkan ilmu. Oleh karena itu, motivasi menjadi ulama merupakan motivasi yang tinggi yang akan membuat siswa rajin belajar, terutama bahasa Arab.

Ulama merupakan penerus para Nabi, ulama merupakan rembulan yang selalu memantulkan cahaya matahari ke bumi, malam akan gelap gulita jika tidak ada cahaya rembulan. Oleh sebab itu, untuk meniadakan cahaya rembulan, tidak perlu meniadakan bumi atau cahaya itu sendiri, namun dengan cara meniadakan rembulan, maka bumi akan gelap gulita.

Matahari adalah lambang Tuhan, cahaya rembulan adalah ilmuilmu Tuhan, dan rembulan adalah kekasih Tuhan, para ulama, dan bumi adalah umat manusia. Ilmu-ilmu Tuhan dicabut bukan dengan cara ilmu itu sendiri yang dihilangkan, melainkan dengan cara mewafatkan para kekasih Allah, para Nabi Allah, para ulama, dalam hadis Nabi saw dijelaskan:

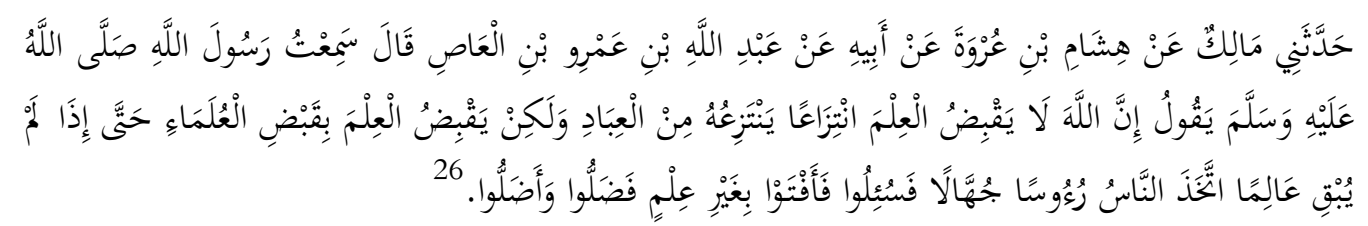

Termasuk dalam motivasi intrinsik dalam pembelajaran bahasa Arab di MTs Salafiyah Syafi'iyah Sukorejo Situbondo, adalah bahwa bahasa Arab merupakan bahasa ahli surga, sebagaimana telah dikutip diatas bahwa bahasa Arab merupakan kunci untuk memahami berbagai sumber ilmu Islam, dan juga berdasarkan hadis Nabi saw.:

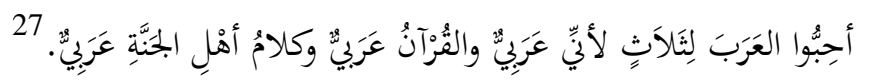

Berdasarkan hadis diatas, terdapat tiga argument yang menjelaskan tentang perintah agar senang terhadap bahasa Arab, pertama karena Rasulullah saw sendiri adalah orang Arab. Kedua, karena bahasa Arab merupakan bahasa al-Qur'an, ini merupakan motivasi intrinsik yang terdapat dalam dua lembaga tersebut sebagaimana yang telah dijelaskan diatas. Ketiga, karena bahasa Arab merupakan bahasa ali surga.

\footnotetext{
${ }^{26}$ Muhammad bin Ismail bin Ibrahim bin Mughirah al-Bukhary, Shahih Bukhari, Juz I, Cet, ke-1, Dar Thauq an-Najah, hlm. 32.

${ }^{27}$ Jalaluddin 'Abdirrahman bin Abi Bakr as-Suyuti, al-Miftahu al-Kabir fi Dhammi azZiyadah ila Jami'i ash-Shaghir, Juz I, Cet. Ke-1, Bairut, Dar al-fkir, hlm. 46; Sulaiman bin Ahmad bin Ayyub Abu al-Qasim al-Thabary, al-Mu'jam al-Kabir, Maktabah al-Ulum wa alHikmah, Juz XI, hlm. 185.
}

$134 \mid$ JURNAL LISAN AL-HAL 
Berdasarkan berbagai motivasi intrinsik inilah semua siswa di dua lembaga tersebut, MTs Salafiyah Syafi'iyah Sukorejo Situbondo dan MTs SA Al-Hidayah Kota Batu-Malang, memiliki semangat yang besar dalam mempelajari bahasa Arab, hal tersebut dapat terlihat dalam proses pembelajaran, baik dalam kelas, belajar kelompok, maupun mengikuti kursus, dan sebagainya.

Berdasarkan pembahasan data diatas tentang motivasi intrinsik dalam pembelajaran bahasa Arab bagi siswa MTs, maka peneliti dapat menggambarkan sebagai berikut:

a. Para siswa ingin memahami dan menggali makna yang tersimpan dalam al-Qur'an.

b. Para siswa ingin melanjutkan pendidikan ke Timur Tengah.

c. Para siswa ingin melancong ke Negara Arab secara gratis

d. Para siswa ingin menjadi ulama dan dai yang popular

e. Para siswa ingin menjadi ahli surga

\section{Motivasi Ekstrinsik dalam Pembelajaran Bahasa Arab}

Di MTs Salafiyah Syafi'iyah Sukorejo Situbondo, berdasarkan data yang diperoleh bahwa para siswa senang terhadap bahasa Arab dan mereka memiliki motivasi yang tinggi dalam mempelajarinya. Hal tersebut disebabkan terdapat beberapa motivasi ekstrinsik, yaitu: pertama, karean guru bahasa Arab selalu memberi pujian dan hadiah pada anak didik. Kedua, karena guru bahasa Arab tidak pernah marah ketika ada murid yang salah, bahkan dia hanya tersenyum. Ketiga, karena guru bahasa Arab mahir dalam berbahasa Arab. Keempat, karena bangunan yang indah dan ruangan kelas yang tersusun rapi dan bersih. Kelima, karena guru bahasa Arab menggunakan permainan dalam menyampaikan materi pelajaran. Keenam, karena keluarga mereka dapat berbahasa Arab.

Di MTs SA Al-Hidayah Kota Batu-Malang, berdasarkan data yang diperoleh bahwa para siswa senang juga terhadap bahasa Arab dan memiliki motivasi yang tinggi dalam mempelajarinya bahasa Arab tersebut. Hal itu disebabkan terdapat beberapa motivasi ekstrinsik, yaitu: pertama, karena selau memulai dan mengakhiri pelajaran dengan berdo'a khusus pada anak didik. Kedua, karena guru bahasa Arab mahir dalam berbahasa Arab. Ketiga, karena guru bahasa Arab tidak pernah marah ketika ada murid yang salah, bahkan dia hanya tersenyum. Keempat, karean guru bahasa Arab selalu memberi pujian dan hadiah pada anak didik. Kelima, karena guru bahasa Arab menggunakan permainan dalam menyampaikan materi pelajaran.

Berdasarkan penjelasan diatas, motivasi ekstrinsik dalam

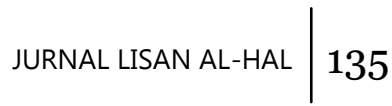


pembelajaran bahasa Arab di dua lembaga tersebut dapat dikelompokkan menjadi, pertama, adanya seorang guru bahasa Arab yang selalu dan senantiasa memberi pujian dan hadiah pada anak didik. Kedua, adanya seorang guru bahasa Arab yang tidak pernah marah ketika terdapat murid yang salah, bahkan memberi senyuman. Ketiga, adanya seorang guru bahasa Arab yang mahir dalam berbahasa Arab. Keempat, karena guru bahasa Arab menggunakan permainan dalam menyampaikan materi pelajaran.

Namun selain persamaan persamaan tersebut, terdapat perbedaan lain yang menjadi motivasi ekstrinsik dalam pembelajarab bahasa Arab di dua lembaga tersebut. MTs Salafiyah Syafi'iyah Sukorejo Situbondo berbeda dengan MTs SA Al-Hidayah Kota Batu-Malang dalam hal Pertama, adanya bangunan yang indah dan ruangan kelas yang tersusun rapi dan bersih. Kedua, adanya keluarga siswa yang dapat berbahasa Arab.

Sedangkan MTs SA Al-Hidayah Kota Batu-Malang berbeda dengan MTs Salafiyah Syafi'iyah Sukorejo Situbondo dalam hal adanya seorang guru bahasa Arab yang selau memulai dan mengakhiri pelajaran dengan berdo'a khusus pada anak didik.

Seorang guru yang selalu memberi apresiasi terhadap siswa, baik itu berupa perkataan (pujian misalnya) atau berupa hadiah (pemberian buku misalnya) akan merangsang siswa untuk semangat dalam melakukan suatu hal, karena apresiasi dari seorang guru merupakan salah satu kebutuhan pokok bagi anak didik, baik anak didik dalam tingkat PUD atau pun dalam tingkat Perguruan tinggi. Menukil istilah Abraham Maslow (1908-1970 M), bahwa apresiasi merupakan salah satu dari hirarki kebutuhan manusia. Apresiasi dengan bentuk pujian dan hadiah tergolong dalam hirarki kebutuhan akan penghargaan (esteem need), kebutuhan ini merupakan kebutuhan tingkat tertinggi kedua setelah kebutuhan aktualisasi diri (Self Actualization Need).

Maslow membagi esteem need dalam dua kategori, yaitu ketegoti tingkat bawah dan kategori tingkat atas. ketegoti tingkat bawah meliputi kebutuhan akan penghargaan dari orang lain, status, perhatian, reputasi, kebanggaan diri, dan kemasyhuran. kategori tingkat atas meliputi penghargaan oleh diri sendiri, kebebasan, kecakapan, keterampilan, dan kemampuan khusus (spesialisasi). Yang membedakan dari dua kategori tersebut adalah sumber penghargaan yang diperoleh. Pada ketegoti tingkat bawah, sumber penghargaan berasal dari orang lain. Sedangkan kategori tingkat atas, sumber penghargaan berasal dari diri sendiri. Penghargaan berupa pujian dan pemberian hadiah tergolong dalam kategori esteem need tingkat bawah, sebab itu berasal dari orang lain.

$136 \mid$ JURNAL LISAN AL-HAL 
Kategori esteem need tingkat bawah akan mengakibatkan hilang rasa percaya dari dan semangat jika orang yang memberi apresiasi tersebut tidak lagi memberi apresiasi atau tidak ada, yang mana dalam hal ini adalah guru.

Termasuk dalam motivasi ekstrinsik dalam dua lembaga tersebut adalah adanya seorang guru bahasa Arab yang tidak pernah marah ketika terdapat murid yang salah, bahkan memberi senyuman. Guru seperti ini menggambarkan sifat seorang guru yang penyabar dan penyayang kepada para muridnya. Dua sifat tersebut, sabar dan sayang, merupakan sifat dasar yang harus dimiliki oleh seorang guru. Sifat sabar tersebut digambarkan oleh Tuhan dalam firman-Nya:

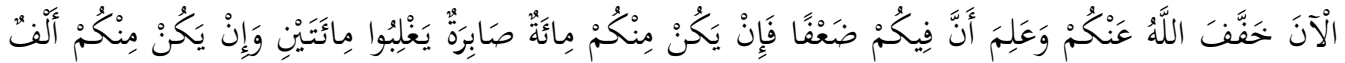

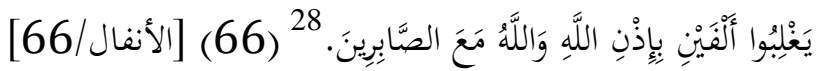

Allah maha mengetahui terhadap kelemahan makhluknya, oleh sebab itu, seandainya ada 100 orang yang sabar, niscaya mereka akan mampu mengalahkan 200 orang kafir. Karena Allah akan selalu menolong hamba-Nya yang memiliki sifat terpuji tersebut. Dan Allah senantiasa orang-orang yang sabar. Begitupula seorang guru, hendaknya ia sabar dalam menghadapi segala tindak tanduk muridnya. Sebab murid adalah individu yang unik, karena dari sekian jumlah siswa memiliki watak dan karakter yang berbeda-beda. Ada yang suka usil, suka bercanda, ada yang pendiam, ada yang aktif, ada yang cerdas, dan ada juga yang lambat. Disinalah dibutuhkan sifat seorang yang penyabar. Dalam firman-Nya yang lain dijelaskan:

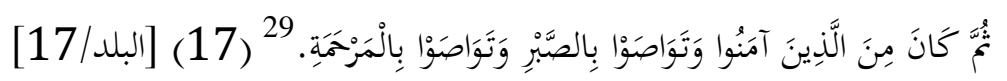

Selain memiliki sifat sabar, seorang guru juga harus memiliki sifat kasih sayang, terutama kepada para anak didiknya. Tidak heran jika yang manjadi salah satu penyebab siswa senang terhadap bahasa Arab adalah seorang guru yang selalu menampakkan sifat sabar dan kasih sayangnya dalam bentuk tidak marah-marah jika ada siswa yang salah, melainkan hanya dengan tersenyum.

Termasuk dalam motivasi ekstrinsik dalam dua lembaga tersebut adalah adanya seorang guru bahasa Arab yang mahir dalam berbahasa Arab. Tak heran jika guru bahasa Arab pandai berbahasa Arab dan selalu

${ }^{28}$ QS. Al-Anfal (08): 66

${ }^{29}$ QS. Al-Balad (90): 17 
mempraktekkannya dalam proses pembelajaran, maka siswa akan senang terhadap bahasa Arab, dan mereka akan terangsang untuk ikut juga berbicara bahasa Arab, sebab seorang siswa membutuhkan contoh atau panutan dalam berbicara bahasa Arab. Disinalah letak pentingnya contoh atau praktek berbicara dalam proses pembelajaran bahasa Arab.

Menukil istilah Jaudat ar-Rukkaby, bahwa terdapat sifat khusus yang harus dimiliki oleh guru bahasa Arab, salah satunya adalah senantiasa berbicara bahasa Arab dan menulis bahasa Arab. ${ }^{30}$ Guru bahasa Arab yang berbicara bahasa Arab dengan baik dan menulis arab dengan baik merupakan suatu media pertama dalam pembelajaran bahasa Arab.

Termasuk juga dalam motivasi ekstrinsik dalam dua lembaga tersebut adalah adanya seorang guru bahasa Arab yang menggunakan media pembelajaran yang sesuai dengan materi bahasa Arab seperti permainan bahasa. Disinilah letak pentingnya metode pembelajaran ${ }^{31}$ dan media pembelajaran. ${ }^{32}$ Seorang guru harus mempunyai kompetensi akademik agar dapat menguasai metode dan media apa saja yang sesuai dengan kondisi anak didik.

Menukil istilah Uril Bahruddin,33 dalam bukunya berjudul Maharotu At-Tadris Nahwa I'dad Mudarris Al-Lughah Arabiyan Al-Kuf'i, bahwa karakteristik seorang guru adalah mempunyai kompetensi akademik yang meliputi pengetahuan yang luas dan mendalam terhadap materi pembelajaran, pemahaman yang sempurna terhadap dasar-dasar psikologi pembelajaran, dan penguasaan terhadap pendekatan, metode, teknik, dan media pembelajaran yang berbeda-beda. ${ }^{34}$

Termasuk dalam motivasi ekstrinsik dalam pembelajaran bahasa Arab di MTs Salafiyah Syafi'iyah Sukorejo Situbondo, adalah adanya

\footnotetext{
${ }^{30}$ Jaudat ar-Rukkaby, Thuruqu Tadrisi Al-Lughah Al-Arabiyah, Cet. Ke-10, (Damaskus, Dar al-Fikr, 2005), hlm. 48.

31 Metode pembelajaran merupakan tingkat perencanaan program yang bersifat menyeluruh yang berhubungan erat dengan langkah-langkah penyampaian materi pelajaran secara prosedural, tidak saling bertentangan, dan tidak bertentangan dengan pendekatan. Acep Hermawan, Metodologi Pembelajaran Bahasa Arab, Cet. Ke-2, (Bandung: PT. Remaja Rosdakarya, 2011), hlm. 168.

32 Menukil istilah Gagne dan Briggs (dalam Arsyad, 2002), media pembelajaran adalah alat yang secara fisik digunakan untuk menyampaikan isi materi pengajaran yang diantaranya terdiri atas buku, tape recorder, kaset, video camera, video camera, film, slide, foto, gambar, grafik, televise dan computer. Abdul Wahab Rosyidi, Media Pembelajaran Bahasa Arab, Cet. Ke-1, (Malang: UIN-Malang Press, 2009), hlm. 26.

${ }^{33}$ Guru bahasa Arab di Fakultas Humaniora dan Budaya universitas Islam Negeri Maulana Malik Ibrahim Malang.

${ }^{34}$ Uril Bahruddin, Maharotu At-Tadris Nahwa I'dad Mudarris Al-Lughah Arabiyan Al$K u f^{\prime} i$, Cet. Ke-1, (Malang: UIN MALIKI Press, 2011), hlm. 49.
}

138 JURNAL LISAN AL-HAL 
bangunan yang indah dan ruangan kelas yang tersusun rapi dan bersih. Salah satu dari tabiat manusia adalah senang kepada segala keindahan atau akrab dengan sebutan estetika. Tak salah kiranya jika yang menjadi salah satu dari senangnya para siswa terhadap pembelajaran bahasa Arab adalah adanya keindahan yang terdapat di lingkungan sekolah. Menukil istilah al-'Araqy, dalam kitab Faidhu al-Qadir, menjelaskan bahwa:

$$
\text { النظافة تدعو إلى الإيمان. }
$$

Kebersihan atau keindahan bukan hanya tabiat manusia, namun juga dapat menarik pada keimanan, tidak heran jika keindahan termasuk hal yang dapat menarik siswa untuk senang dalam belajar bahasa Arab. Dalam hadis gharib dijelaskan:

باليهود.

Dan juga termasuk dalam motivasi ekstrinsik dalam pembelajaran bahasa Arab di MTs Salafiyah Syafi'iyah Sukorejo Situbondo, adalah adanya keluarga siswa yang dapat berbahasa Arab. Keluarga yang senantiasa menggunakan bahasa Arab dalam kehidupan sehari-hari akan mendorong anak didik untuk ikut juga berbahasa Arab, sebagaimana yang telah dijelaskan diatas, bahwa guru yang senantia menggunakan bahasa Arab dalam proses pembelajaran akan merangsang anak didik untuk ikut juga menirukan apa yang diucapkan oleh guru. Dipandangn dari segi diperolehnya motivasi ini, maka motivasi ini disebut dengan motivasi kedua atau mitivasi social (الدوافع الثانوية أو الإجتماعية).

Termasuk dalam motivasi ekstrinsik dalam pembelajaran bahasa Arab di MTs SA Al-Hidayah Kota Batu-Malang, adalah adanya seorang guru bahasa Arab yang selau memulai dan mengakhiri pelajaran dengan berdo'a khusus pada anak didik. Motivasi ini berhubungan dengan tabiat manusia, berupa ketenangan dan keselamatan diri, motivasi ini tergolong motivasi agama, moral, dan kemanan, sehingga akan mengantarkan seseorang untuk mencari ridha Allah SWT., keselamatan pada hari akhirat dan masuk surga. ${ }^{37}$

${ }^{35}$ Al-Manawi, Faidhu al-Qadir, Juz XII, Cet. Ke-1, (Libanun: Dar al-Kutub al-Ilmiyah, 1994), hlm. 185 .

36 al-Tirmidzy, Sunan al-Tirmidzy, hlm. 198; Jalaluddin al-Suyuthi, Jami'u al-Ahadits li Jalaluddin al-Suyuthi, Juz VIII, hlm. 72.

37 Abdul Aziz bin Muhammad, 'Ilmu an-Nafsi al-Da'wa, (Riyadh: Dar al-Muslim, 2003), hlm. 79. 
Dalam hadis Nabi saw. dijelaskan:

$$
\begin{aligned}
& \text { حدثنا عمر بن حفص حدثنا أبي حدثنا الأعمش سمعت أبا صالح عن أبي هريرة رضي الله عنه قال: قال النبي }
\end{aligned}
$$

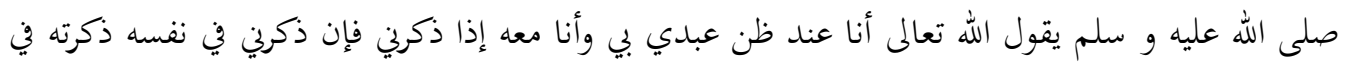

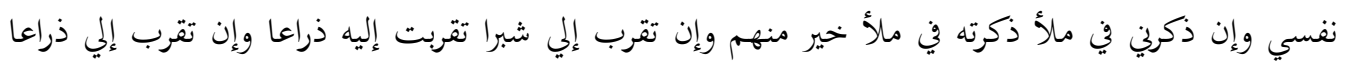

$$
\begin{aligned}
& \text { تقربت إليه باعا وإن أتاني يمشي أتيته هرولة. }
\end{aligned}
$$

Dalam hadis lain juga dijelaskan tentang perbedaan orang yang menyebut nama Allah SWT. dengan orang yang tidak menyebut nama Allah dengan perumpamaan orang yang hidup dengan orang yang mati.

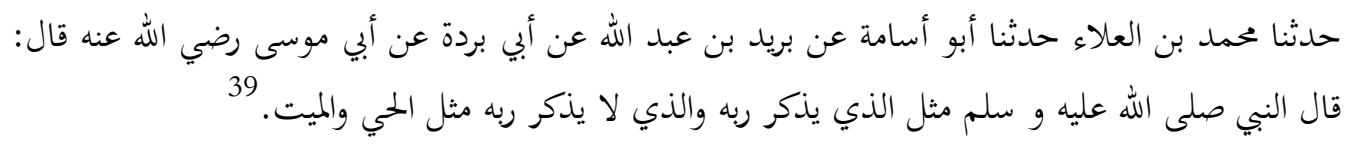

Berdasarkan pembahasan data diatas tentang motivasi ekstrinsik dalam pembelajaran bahasa Arab bagi siswa MTs, maka peneliti dapat menggambarkan sebagai berikut:

a. Guru bahasa Arab selalu dan senantiasa memberi apresiasi berupa pujian dan hadiah pada anak didik.

b. Guru bahasa Arab yang memiliki sifat kasih sayang terdapat anak didik

c. Guru bahasa Arab yang mahir dalam bercakap bahasa Arab.

d. Guru bahasa Arab menggunakan media pembelajaran yang sesuai dengan materi pembelajaran.

e. Lingkungan kelas yang indah.

f. Keluarga siswa yang bercakap bahasa Arab.

g. Guru bahasa Arab yang selau memulai dan mengakhiri pelajaran dengan berdo'a khusus pada anak didik.

Untuk memperjalas dana mempermudah, Peneliti akan menggambarkan motivasi siswa tingkat MTs dalam pembelajaran bahasa Arab sebagai berikut:

38 al-Bukhary, Shahih Bukhari, Juz VI, hlm. 2694; Muslim bin Hujjaj Abu al-Husain alQusyairi al-Naisaburi, Shahih Muslim, Juz IV, (Bairut: Dar Ihya' al-Turats al-Arabi), hlm. 2061

39 al-Bukhary, Shahih Bukhari, Juz V, hlm. 2353.

$140 \mid$ JURNAL LISAN AL-HAL 


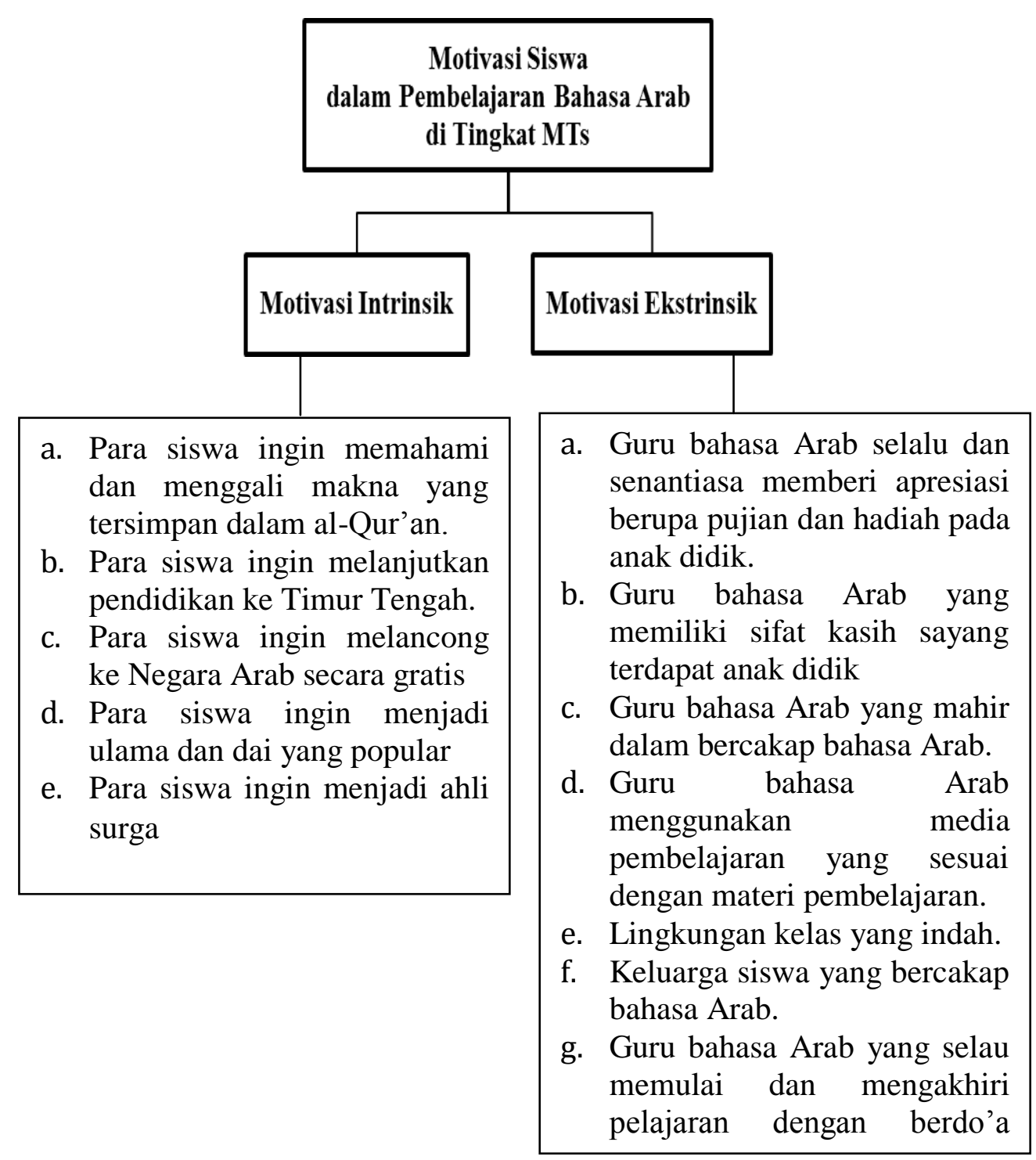

Gambar 1.1: Motivasi Siswa MTs dalam Pembelajaran Bahasa Arab

\section{Simpulan}

Berdasarkan data yang yang diperoleh, analisis, pembahasan dan hasil dari pembahasan tersebut, maka peneliti sampai pada suatu kesimpulan sebagai berikut:

1. Motivasi Intrinsik dalam Pembelajaran Bahasa Arab bagi Siswa MTs Salafiyah Syafi'iyah Sukorejo Situbondo dan MTs SA ALHIDAYAH Kota Batu-Malang, peneliti menemukan titik persamaan tentang motivasi 
intrinsik siswa dalam pembelajaran bahasa Arab. Pertama, siswa senang belajar bahasa Arab karena bahasa Arab merupakan bahasa alQur'an. Kedua, siswa senang belajar bahasa Arab karena ingin melanjutkan pendidikan ke Timur Tengah. Selain persamaan tersebut, terdapat juga perbedaan tentang motivasi intrinsik siswa dalam pembelajaran bahasa Arab. MTs Salafiyah Syafi'iyah Sukorejo Situbondo berbeda dengan MTs SA Al-Hidayah Kota Batu-Malang, yakni siswa MTs Salafiyah Syafi'iyah Sukorejo Situbondo ingin menjadi ahli surga. Sedangkan MTs SA Al-Hidayah Kota Batu-Malang berbeda dengan MTs Salafiyah Syafi'iyah Sukorejo Situbondo yakni siswa MTs SA Al-Hidayah Kota Batu-Malang ingin melancong ke Negara Arab secara gratis dan ingin menjadi ulama dan dai yang popular.

2. Motivasi Ekstrinsik dalam Pembelajaran Bahasa Arab Siswa MTs Salafiyah Syafi'iyah Sukorejo Situbondo dan MTs SA Al-Hidayah Kota Batu-Malang, peneliti menemukan titik persamaan tentang motivasi ekstrinsik siswa dalam pembelajaran bahasa Arab. Pertama, adanya guru bahasa Arab selalu dan senantiasa memberi apresiasi berupa pujian dan hadiah pada anak didik. Kedua, adanya guru bahasa Arab yang memiliki sifat kasih sayang terdapat anak didik. Ketiga, adanya guru bahasa Arab yang mahir dalam bercakap bahasa Arab. Keempat, adanya guru bahasa Arab menggunakan media pembelajaran yang sesuai dengan materi pembelajaran. Selain persamaan tersebut, terdapat juga perbedaan tentang motivasi ekstrinsik siswa dalam pembelajaran bahasa Arab. MTs Salafiyah Syafi'iyah Sukorejo Situbondo berbeda dengan MTs SA Al-Hidayah Kota Batu-Malang, yakni adanya lingkungan kelas MTs Salafiyah Syafi'iyah Sukorejo Situbondo yang indah dan adanya keluarga mereka yang bercakap bahasa Arab dalam kehidupan sehari-hari. Sedangkan MTs SA AlHidayah Kota Batu-Malang berbeda dengan MTs Salafiyah Syafi'iyah Sukorejo Situbondo yakni adanya guru MTs SA Al-Hidayah Kota BatuMalang bahasa Arab yang selau memulai dan mengakhiri pelajaran dengan berdo'a khusus pada anak didik.

\section{DAFTAR PUSTAKA}

QS. Al-An'am (06): 50; Al-Anfal (08): 66; Yusuf (12): 2; Ar-Ra'd (13): 16; An-Nahl (16): 103; Thaahaa (20): 113; Asy-Syu'ara' (26): 193-195; Az-Zumr (39): 9, 28; Az-Zukhruf (43): 3; Al-Ahqaf (46): 12; Al- 
Mujadalah (58): 11; Al-Balad (90): 17.

Abdillah, Muhammad bin Buhadir bin 'Abdillah az-Zarkasyi Abu, 1405 H., al-Manstur fi al-Qawaid, Juz I, Cet., Ke-3, Kuwait, Wazara al-Auqaf wa as-Syuun al-Islamy.

Ahmadi, Abu dan Widodo Supriono, Psikologi Belajar, Jakarta, Rineka Cipta, 2003.

al-Bukhary, Muhammad bin Ismail bin Ibrahim bin Mughirah, Shahih Bukhari, Juz I, V, \& VI, Cet, ke-1, Dar Thauq an-Najah.

al-Hambaly, Ibn Liham al-Ba'ily al-Damasyqy, al-Qawaid wa al-Fawaid alUshuliyah wa Ma Yatbi'uha min al-Ahkam al-Far'iyyah, Juz I, Maktabah al-Madinah, 1999.

Al-Manawi, Faidhu al-Qadir, Juz XII, Cet. Ke-1, Libanun, Dar al-Kutub alIlmiyah, 1994.

al-Naisaburi, Muslim bin Hujjaj Abu al-Husain al-Qusyairi, Shahih Muslim, Juz IV, Bairut, Dar Ihya' al-Turats al-Arabi.

al-Quzwaini, Muhammad bin Yazid Abu 'Abdillah, Sunan Ibn Majah, Juz I, Bairut, Dar al-Fikr.

al-Suyuthi, Jalaluddin, Jami'u al-Ahadits li Jalaluddin al-Suyuthi, Juz VIII.

al-Thabary, Sulaiman bin Ahmad bin Ayyub Abu al-Qasim, al-Mu'jam alKabir, Maktabah al-Ulum wa al-Hikmah, Juz XI.

al-Tirmidzy, Abi 'Isa Muhammad bin 'Isa bin Surah, Sunan al-Tirmidzy, Juz IV, Bairut, Dar al-Fikr.

al-Zarkasyi, Badru ad-Din Muhammad bin 'Abdullah, al-Bahru al-Muhith fi Ushul al-Fiqh, Juz I, Cet., Ke-1, Bairut, Dar al-Kutub al-'Ilmiyah, 2000.

as-Sajsatany, Abi Daud Sulaiman bin Asy'ats, Sunan Abi Daud, Juz III, Bairut, Dar al-Fikr.

as-Suyuti, Jalaluddin 'Abdirrahman bin Abi Bakr, al-Miftahu al-Kabir fi Dhammi az-Ziyadah ila Jami'i ash-Shaghir, Juz I, Cet. Ke-1, Bairut, Dar al-Fkir.

asy-Syaibany, Ahmad bin Hambal Abu 'Abdillah, Musnad al-Imam Ahmad bin Hambal, Juz II, Kairo, Muassasah Qurthubah.

asy-Syuhud, Aly bin Nayif, al-Waqtu wa Ahammiyatuhu fi Hayati al-Muslim, Juz III.

Aziz, Abdul bin Muhammad, 'Ilmu an-Nafsi al-Da'wa, Riyadh, Dar alMuslim, 2003.

Bahruddin, Uril, Maharotu At-Tadris Nahwa I'dad Mudarris Al-Lughah Arabiyan Al-Kuf'i , Cet. Ke-1, Malang, UIN MALIKI Press, 2011.

Dimyati dan Mudjiono, Belajar dan Pembelajaran, Jakarta, Rineka Cipta, 2002,

Djamarah, Syaiful Bahri, Prestasi Belajar dan Kompetensi Guru, Surabaya, 
Usaha Nasional, 1994.

Ghuddah, Abdul Fattah Abu, Qimah az-Zaman 'inda al-'Ulama, Cet, ke-10, Maktab al-Mathbu'at al-Islamiyah.

Hamalik, Oemar, Psikologi Belajar dan Mengajar, Bandung, Sinar Baru Agensindo, 2009.

2013.

Hermawan, Acep, Metodologi Pembelajaran Bahasa Arab, Cet. Ke-2, Bandung, PT. Remaja Rosdakarya, 2011.

Ihsan, Fuad, Dasar-dasar Kependidikan, Jakarta, Rineka Cipta, 2003.

Jaudat ar-Rukkaby, Thuruqu Tadrisi Al-Lughah Al-Arabiyah, Cet. Ke-10, Damaskus, Dar al-Fikr, 2005.

Rosyidi, Abdul Wahab, Media Pembelajaran Bahasa Arab, Cet. Ke-1, Malang, UIN-Malang Press, 2009.

Sardiman, Interaksi dan Motivasi Belajar, Jakarta, Raja Grapindo Persada, 2003.

Sukmadinata, Nana Syaodih, Landasan Psikologi Proses Pendidikan, Bandung, Remaja Rosdakarya, 2003.

UURI No. 20 Tahun 2003, Tentang Sistem Pendidikan Nasional, Jakarta, Kreasi Jaya Utama

Zaenuddun, Radliyah, dkk. Metodologi dan Strategi Alternatif Pembelajaran Bahasa Arab, Yogyakarta, Pustaka Rihlah Group, 2005.

$144 \mid$ JURNAL LISAN AL-HAL 